\title{
Effectiveness of an Image-based Sorter to Select for Kernel Color within Early Segregating Hard Winter Wheat (Triticum aestivum L.) Populations
}

\author{
D. Brabec ${ }^{1 *}$, M.J. GutTIERI ${ }^{2}$, T. PEARSON ${ }^{3,4}$ and B. CARSRUD ${ }^{5,6}$ \\ ${ }^{1}$ USDA, Agricultural Research Service, Center for Grain and Animal Health Research, Stored Product Insect \\ and Engineering Research Unit, 1515 College Avenue, Manhattan, KS 66502, USA \\ ${ }^{2}$ USDA, Agricultural Research Service, Center for Grain and Animal Health Research, Hard Winter Wheat \\ Genetics Research Unit, 1515 College Avenue, Manhattan, KS 66502, USA \\ ${ }^{3}$ ARS-USDA, Manhattan, KS, USA (previous address) \\ ${ }^{4}$ Amgen, 1 Amgen Center Drive, Thousand Oaks, CA 91320, USA \\ ${ }^{5}$ South Dakota State University, Brookings, SD 57007, USA (previous address) \\ ${ }^{6}$ SGS Seed Services, 236, 32 ${ }^{\text {nd }}$ Ave., Brookings, SD 57006, USA
}

(Received 15 December 2016; Accepted 8 March 2017)

\begin{abstract}
This study evaluated the effectiveness of an image sorter to select for kernel color within early generations of segregating hard winter wheat populations. The wheat crosses originated from different combinations of white and red parents. Three generations $\left(\mathrm{F}_{3}, \mathrm{~F}_{4}\right.$ and $\left.\mathrm{F}_{5}\right)$ of sorting were applied to six segregating populations. At each generation, samples of whitesorted, red-sorted, and unsorted populations, along with the parents of the populations, were planted in replicated trials at multiple locations. The sorter processed $1 \mathrm{~kg}$ sized samples in $\sim 30 \mathrm{~min}$ and samples were sorted for 108 plots per season. $\sim 10 \%$ of the $\mathrm{F}_{3}$ populations were sorted and planted as white-sort population. This resulted in minimal changes in the $\%$ of white kernels. $\sim 3 \%$ of the $\mathrm{F}_{4}$ and $\mathrm{F}_{5}$ populations were sorted and planted as white-sorted populations and significant advancement occurred. The $\mathrm{F}_{6}$ populations of white-sorted samples from Dakota Lake ranged from $80 \%$ to $92 \%$ white kernels. The $\mathrm{F}_{6}$ populations from Brookings ranged from $53 \%$ to $83 \%$ white kernels. Sorting for red seed decreased the frequency of white seed as compared to the unsorted reference populations; however reductions, of white seeds in the red populations, were modest and required three cycles of selection for significant effect. The effectiveness of the image-sorter varied with population and environment and sorting methods.
\end{abstract}

Keywords: image sorting, seed color, wheat breeding

\section{Introduction}

Red wheat cultivars have been the predominant color class produced in the central United States for decades (Paulsen and Shroyer 2008). However, many consumers prefer the flavor and appearance of whole grain wheat products processed from white wheat (Taylor et al. 2005; Talbert et al. 2013). A product with higher dietary fiber can be prepared from

*Corresponding author; E-mail: daniel.brabec@ars.usda.gov; Phone: 785-776-2731. 
white wheat flour (Chang et al. 1995; Williams 2013), because more of the white wheat bran can be included in the flour without impacting appearance. Thus, millers can obtain higher flour yields with the white wheat varieties verses the red wheat varieties (Ambalamaatil et al. 2006). The kernel color of hexaploid wheat is a quantitative trait determined primarily by three additive genes on the group-3 chromosomes. Red kernel color is dominant to white (Metzger and Silbaugh 1970).

White genotypes are not visually identifiable until $\mathrm{F}_{3}$ kernels (Sherman et al. 2008). In a cross between a homozygous red parent with red alleles at all three loci, and a homozygous white parent, less than $2 \%$ of the $\mathrm{F}_{2}$ progeny plants are expected to express white kernel color in the $\mathrm{F}_{3}$ seed. Many other minor genes reportedly modify the expression of kernel color (Kumar et al. 2009), and the environment will also significantly affect color (Matus Cadiz et al. 2003; McCaig et al. 2006; Lukow et al. 2013).

Cooper and Sorrells (1984) predicted that the best generation in which to select white kernels in a red/white cross was $\mathrm{F}_{3}$ seed, given that many loci are likely to be segregating for yield. They predicted that this early selection would result in the highest frequency of white seeds with high yield alleles. They also noted that it was important to retain adequate population sizes to be able to recover desirable genotypes for yield alleles in later generations. Knott et al. (2008) evaluated alternative breeding strategies for selecting of white kernel color in wheat. They concluded that there was no statistically significant difference between early and late-generation selection approaches. Neither study considered the effect of sequential generations of sorting.

Red wheat varieties dominate many hard wheat growing regions and white progeny may be considered undesirable because of the potential susceptibility to pre-harvest sprouting. Breeders may target the selection of red genotypes from red/white crosses. Elimination of white genotypes from red/white breeding populations poses a particular challenge as recessive white genes continue to segregate from populations through successive generations of inbreeding. White genotypes have even been recovered from red/ red crosses which contained red alleles at complementary loci. In the case of the cultivar 'Gary' (Souza et al. 2004), a white wheat was derived from a cross of two red wheat varieties. High throughput tools to eliminate white segregates may be useful to breeders who are developing red wheat varieties.

Pearson et al. (2008) described the development of an image sorter to separate white from red wheat kernels and this was the system used. It processes $\sim 20$ seeds per second. A single channel of grain was feed past a camera and an air ejection nozzle. This system and its image processing and parameter selection methods were the basis for models of seed sorters which became commercially available from National Mft (Lincoln, NE, USA). Dowell et. al (2009) studied the potential for a single kernel NIR sorting to genetically advance hardness, protein, and color traits in hard winter wheat samples. Sorter technology continues to advancements. Delwiche (2008) and Pearson et al. (2013) developed single channel sorters which alternately strobed both visible and infrared light sources onto wheat seeds as they passed by a sensor and enhanced seed sorting measurements for wheat. Many other researchers and equipment manufactures test and develop sorters such as the QSorter from QualySense (Switzerland). Flat-bed scanners and soft- 
ware have been developed to measure seed size and color value (Whan 2014). Image sorters have become cost-effective technology for breeding, but scientific reports using sorting over many generations are lacking. The objective of this study was to evaluate the multi-year use of the single channel image sorter for both white and red seed selection in early generation samples in a hard wheat segregating populations.

\section{Materials and Methods}

\section{Plant materials and field plots}

Six $\mathrm{F}_{3}$ segregating populations were used. Table 1 identifies these populations and their hard white winter and hard red winter wheat parents. White parents included 'Alice' (PI 644223) (Ibrahim et al. 2008), 'Danby' (PI 648010), and 'NuDakota' (PI 643089). Red parents included 'CDC Falcon' (PI 619610), 'Darrell' (PI 644224) (Ibrahim et al. 2008), 'Overland' (NE01643, PI 647959) (Baenziger et al. 2008), 'Overley’ (PI 634974), and 'Postrock' (PI 643093). All female parents were white, and all male parents were red. $\mathrm{F}_{2}$ plots of each segregating population were planted in Brookings, SD, USA in fall 2009. The $\mathrm{F}_{3}$ populations were harvested in 2010 at Brookings. The populations were separated into five sub-samples; white-sorted, red-sorted, unsorted, white-parent, and red-parent. These sub-samples were planted at three locations; Brookings, Dakota Lakes, and Winner, South Dakota.

The experimental design was a split plot with three replications for each sample at each location and year. The main plots were the six wheat populations (Table 1), which were randomized within each replication. The five, randomized subplots were the white-sort population, red-sort population, unsorted population, and the two parent cultivars. At each location, 90 subplots were planted: 6 populations $\times 5$ subplots $\times 3$ replications. Each subplot was planted with $\sim 14 \mathrm{~g}$ seeds into four rows within a $1.2 \mathrm{~m}^{2}$ area. Agronomic management of experimental areas is described in Supplemental Information. Each year at harvest, the inner two rows of each 4-row subplot were cut with a hand-sickle. Inner rows were threshed using a stationary threshing machine, with care taken to thoroughly clean the thresher with compressed air between samples.

Brookings averages $\sim 610 \mathrm{~mm}$ of rain while Dakota Lakes and Winner average $\sim 560 \mathrm{~mm}$ (Arguez et al. 2010). Winner location wheat was abandoned for Cycle I due to excessive field contamination from volunteer wheat. The populations harvested from the Brookings in Cycle I trial, $\mathrm{F}_{4}$ kernels, were used to plant at both Brookings and Winner locations for Cycle II.

\section{Kernel sorting}

A single-channel, image sorter was used in this study as described by Pearson et al. (2008). Seeds were fed to the camera field of view ( 20 seeds/sec). A color camera and computer captured images as each kernel exited the feeder chute. The seed images were processed into several parameters. Sorting thresholds were set with calibration files and 
determined if the seeds were diverted as white-sorted or red-sorted populations with the air nozzles. A positive identification and ejection strategy was used. For the white-sort, kernels similar to the white-calibration seeds were diverted to the reject hopper. For the red-sort, kernels similar to the red-calibration seeds were diverted to the reject hopper.

Prior to sorting samples, calibration files were compiled. Reference samples were prepared from each parent population. 200 hand-picked red seeds and 200 hand-picked white seeds were ran through the sorter to collect their images. An image analysis program processes the 400 images into 192 parameters per image. Then, discriminate analysis software determined the three parameters that best separated the red and white parent populations. The strength of each calibration depended on the actual visual contrast of the reference samples. High contrasting samples produced calibration parameters that separated well. Low contrasting samples had reduced sorting ability. Hard white wheat verses hard red wheat from each location can have a range of contrast. Calibration files were made for each population and each location and each year using the parent samples. Each calibration file was applied to the related populations.

All $\mathrm{F}_{3}$ populations were grown at Brookings and provided seeds for plots at all three locations. $126 \mathrm{~g}(14 \mathrm{~g} /$ plot $\times 3$ plots $\times 3$ locations $)$ of white-sorted seed was needed. The first pass through the sorter with the $\mathrm{F}_{3}$ populations did not yield enough seed. Additional sort passes were required using the mixed population to accumulate sufficient quantities of $\mathrm{F}_{3}$ white-sorted seed. For the $\mathrm{F}_{4}$ and $\mathrm{F}_{5}$ populations, the seed was grown at each location. Plenty of white-sorted seed was accumulated with the first pass, over the required $42 \mathrm{~g}(14 \mathrm{~g} /$ plot $\times 3$ plots $\times 1$ location $)$. Then, the white-sorted subsample was sorted a second time.

\section{Phenotypic evaluation of kernel color}

Three $\times 100$-kernel subsamples of the white-sorted, red-sorted, unsorted, and parent populations were evaluated for kernel color using a seed staining method (USDA 2006). This staining procedure was modified to improve color differences. Seeds were soaked with a more diluted alkaline solution ( $1 \mathrm{~g} \mathrm{KOH}$ per $25 \mathrm{ml}$ bleach, $6 \% \mathrm{NaClO})$ and soaked for a longer period, $8 \mathrm{~min}$ rather than $2 \mathrm{~min}$. The solution was warmed to $40{ }^{\circ} \mathrm{C}$ before applying to the seeds. Tannins in the seed coat of white kernels typically stained straw-yellow while the red kernels typically stained a brown or brick-red.

\section{Statistical analysis}

For seed color traits of unsorted seeds, the expected frequencies of plants producing white seed in populations segregating for red alleles at $m$ loci after with $n$ generations of inbreeding were estimated as $\left[\left(1-(0.5)^{n}\right) / 2\right]^{m}$. For the sorting experimental data, the measured frequency of white seed in grain samples was analyzed using generalized linear mixed models in PROC GLIMMIX in SAS v. 9.3 (SAS Institute, Cary, NC) for data with a binomial distribution and the default logit link. Within each cycle of selection, the location ( 2 or 3 levels), population (6 levels), and treatment (3 levels) were analyzed as fixed 
effects. The random effects were replications, main plots nested in replications, and subsamples nested within subplots. Satterthwaite's approximation was used to adjust degrees of freedom in the analyses of variance. Within each population and in each location, the significance of sorting at each cycle of selection was tested by comparing the frequency of white seed in the sorted sample to the frequency of white seed in the unsorted sample using the SLICEDIFF option in LSMEANS. Gains from selection were calculated as the difference between the least squares means of the sorted and unsorted treatments on the native, inverse-link scale for each population, cycle, and environment.

\section{Results}

\section{Unsorted populations}

The frequencies of white seed in the six segregating and unsorted populations are shown (Table 1). The $\mathrm{F}_{3}$ frequency ranged from 0.273 , with population-A, down to 0.023 , in population-F. The frequency of white seed increased with generations of inbreeding in unsorted populations of A, D, E, and F. However, the frequency of white seed in the unsorted populations of $\mathrm{B}$ and $\mathrm{C}$ did not increase as expected. The results for the $\mathrm{B}$ and $\mathrm{C}$ populations suggest that unintended selection acted on these populations which reduced the frequency of white seed. The genetically expected frequency of unsorted and homozygous white-seeded plants in the $\mathrm{F}_{3}$ generation for populations segregating for red alleles at one, two, and three loci are $0.25,0.0625$, and 0.0156 , respectively. The expected frequency of white seed by $\mathrm{F}_{6}$ increases to $0.469,0.220$, and 0.103 , respectively (Table 2).

Table 1. Frequency of white seed in unsorted segregating populations over the three years of study

\begin{tabular}{|c|c|c|c|c|c|}
\hline \multirow{2}{*}{ Population } & \multirow{2}{*}{ Pedigree } & \multicolumn{4}{|c|}{ Frequency of White Seed (Confidence Interval) } \\
\hline & & $\mathrm{F}_{3}$ & $\mathrm{~F}_{4}$ & $\mathrm{~F}_{5}$ & $\mathrm{~F}_{6}$ \\
\hline A & $\begin{array}{c}\text { Alice/ } \\
\text { CDC Falcon }\end{array}$ & $\begin{array}{c}0.273 \\
(0.207,0.350)\end{array}$ & $\begin{array}{c}0.410 \\
(0.346,0.477)\end{array}$ & $\begin{array}{c}0.471 \\
(0.431,0.513)\end{array}$ & $\begin{array}{c}0.500 \\
(0.470,0.529)\end{array}$ \\
\hline $\mathrm{B}$ & $\begin{array}{l}\text { Danby/ } \\
\text { Postrock }\end{array}$ & $\begin{array}{c}0.143 \\
(0.099,0.202)\end{array}$ & $\begin{array}{c}0.138 \\
(0.107,0.176)\end{array}$ & $\begin{array}{c}0.179 \\
(0.154,0.206)\end{array}$ & $\begin{array}{c}0.152 \\
(0.134,0.170)\end{array}$ \\
\hline $\mathrm{C}$ & $\begin{array}{l}\text { Alice/ } \\
\text { Overley }\end{array}$ & $\begin{array}{c}0.142 \\
(0.099,0.201)\end{array}$ & $\begin{array}{c}0.052 \\
(0.038,0.071)\end{array}$ & $\begin{array}{c}0.073 \\
(0.060,0.088)\end{array}$ & $\begin{array}{c}0.087 \\
(0.074,0.101)\end{array}$ \\
\hline $\mathrm{D}$ & $\begin{array}{l}\text { NuDakota/ } \\
\text { Darrell }\end{array}$ & $\begin{array}{c}0.100 \\
(0.065,0.150)\end{array}$ & $\begin{array}{c}0.117 \\
(0.090,0.151)\end{array}$ & $\begin{array}{c}0.158 \\
(0.136,0.184)\end{array}$ & $\begin{array}{c}0.191 \\
(0.171,0.212)\end{array}$ \\
\hline $\mathrm{E}$ & $\begin{array}{l}\text { Danby/ } \\
\text { Darrell }\end{array}$ & $\begin{array}{c}0.047 \\
(0.026,0.082)\end{array}$ & $\begin{array}{c}0.094 \\
(0.071,0.123)\end{array}$ & $\begin{array}{c}0.133 \\
(0.113,0.156)\end{array}$ & $\begin{array}{c}0.223 \\
(0.202,0.246)\end{array}$ \\
\hline $\mathrm{F}$ & $\begin{array}{l}\text { NuDakota/ } \\
\text { Overland }\end{array}$ & $\begin{array}{c}0.023 \\
(0.010,0.051)\end{array}$ & $\begin{array}{c}0.060 \\
(0.044,0.080)\end{array}$ & $\begin{array}{c}0.120 \\
(0.130,0.177)\end{array}$ & $\begin{array}{c}0.144 \\
(0.128,0.163)\end{array}$ \\
\hline
\end{tabular}

$\dagger$ limits of the $95 \%$ confidence interval (CI) given in parentheses. Frequencies in $\mathrm{F}_{4}-\mathrm{F}_{6}$ generations were averaged over all field locations per year. 
Table 2. Expected genetic frequencies of white seed for populations segregating for red alleles at one, two, or three loci over several generations of inbreeding

\begin{tabular}{|c|c|c|c|c|}
\hline \multirow{2}{*}{$\begin{array}{c}\text { Segregating Red } \\
\text { Loci }\end{array}$} & \multicolumn{4}{|c|}{ Expected Frequency of White Seed } \\
\cline { 2 - 5 } & $\mathrm{F}_{3}$ & $\mathrm{~F}_{4}$ & $\mathrm{~F}_{5}$ & $\mathrm{~F}_{6}$ \\
\hline 1 & 0.250 & 0.375 & 0.438 & 0.469 \\
\hline 2 & 0.062 & 0.141 & 0.191 & 0.220 \\
\hline 3 & 0.016 & 0.053 & 0.084 & 0.103 \\
\hline
\end{tabular}

\section{Initial sorting of $F_{3}$ populations}

The effect of the initial sorting treatment on the frequency of white seed in the $\mathrm{F}_{3}$ seed lots for planting in Cycle I increased relative to the unsorted sample in every population. The estimated amount of white sorted seed was $\sim 30 \%$ per populations but varied with the population (Fig. 1 and Table $\mathrm{S} 1 *$ ). The red-sort treatment did not decrease the frequency of white seed relative to the unsorted samples.

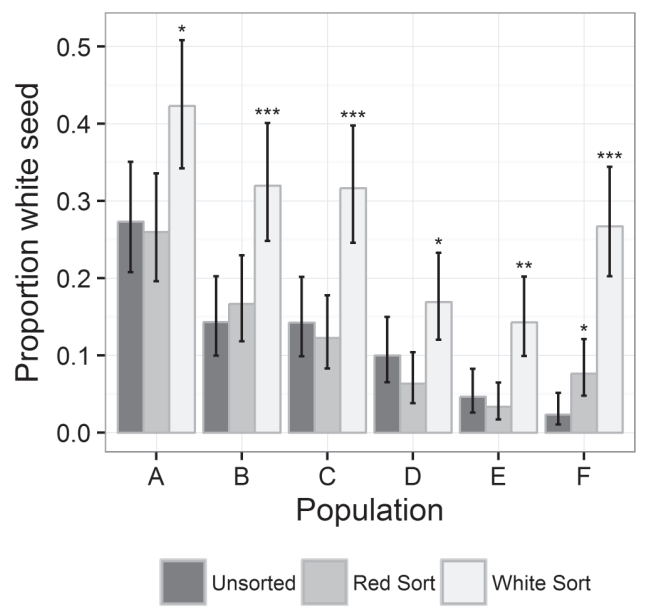

Figure 1. $\mathrm{F}_{3}$ samples and proportions of white seeds in the unsorted, red-sort, and white-sort for the segregating populations. Error bars represent the $95 \%$ C.I. of the mean. $* * *, * * *$ indicate significant differences from unsorted control at $p<0.05,0.01,0.001$, respectively

\section{Selection for white wheat}

The effect of the sorting treatments on the frequency of white seed in harvested grain varied with the population and the growing environment and season. With each subsequent selection cycle, the effect of selection became much greater than interaction effects with population and location, as indicated by the much larger $F$-values for color selection

*Further details about the Electronic Supplementary Material (ESM) can be found at the end of the article. 

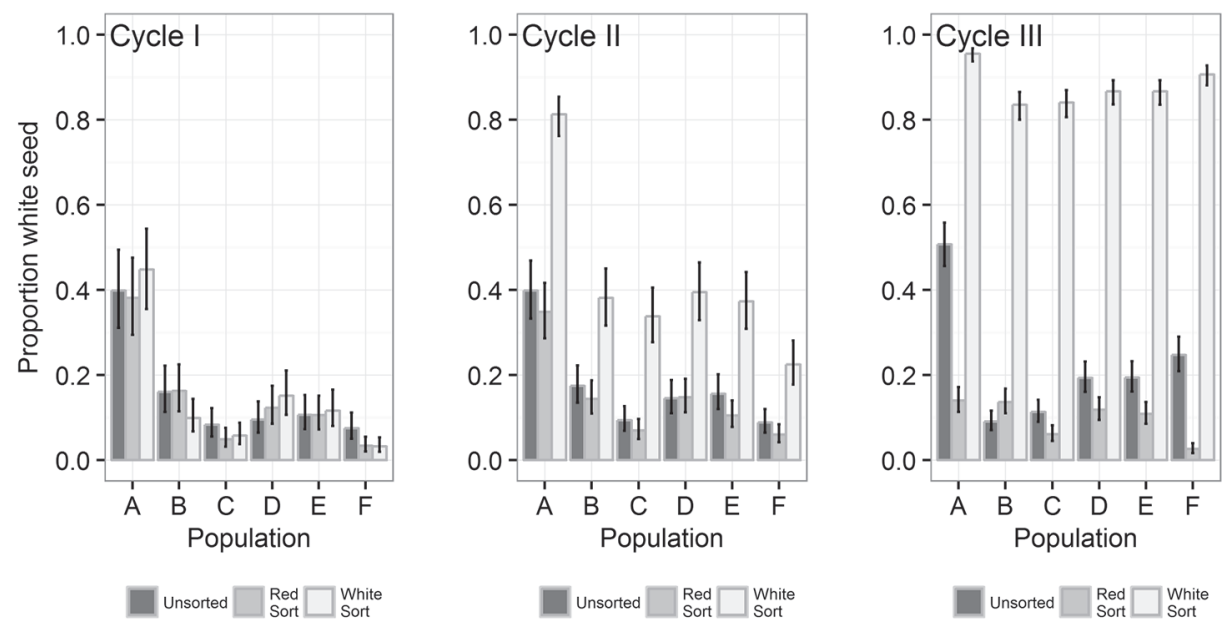

Figure 2. Proportions of white seed in the unsorted, red-sort, and white-sort samples grown at Dakota Lakes, $\mathrm{SD}$ after sequential cycles of selection for each segregating populations
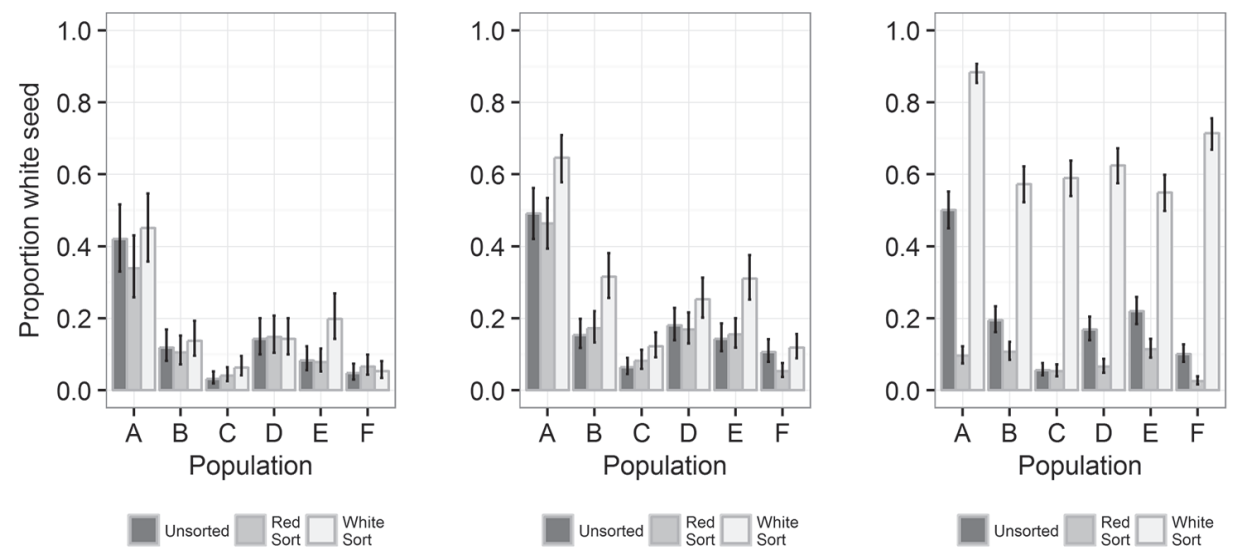

Figure 3. Frequency of white seeds in the unsorted, red-sort, and white-sort samples grown at Brookings, SD after Cycle I, Cycle II, and Cycle III for each segregating population

than for interaction effects (Table S2). The frequency of white seed from sequential cycles is shown for populations grown at Dakota Lakes (Fig. 2). These trends are similar to the effects of selection at Brookings (Fig. 3) and Winner (Fig. S2).

In Cycle I and sorting of $\mathrm{F}_{3}$ seed, the results were rather dismal in the advancement of white $\mathrm{F}_{4}$ seed. Minimal positive gains were observed for only two populations. And small negative responses were observed for three populations sorted for white seed at Dakota Lakes. Gain from selection for white seed at each cycle was evaluated as the differences 
in the frequency of white sorted population and the unsorted population in each environment (Fig. S3).

In Cycle II and sorting of $\mathrm{F}_{4}$ seed, the frequency of harvested white $\mathrm{F}_{5}$ seed in whitesorted populations was consistently greater than in unsorted populations. Positive gains from selection were obtained for five of the populations at all three locations. The magnitude of the gains varied among the populations and environments. The gains in white population were better for samples grown at Dakota Lakes rather than Brookings. Gain from selection after Cycle II was greatest with A-Alice/CDC Falcon at Dakota Lakes, where the gain was $>0.4$.

In Cycle III and sorting of $\mathrm{F}_{5}$ seed, positive changes in the frequency of white seed were consistently produced and were obtained for all six, $\mathrm{F}_{6}$ populations and at three locations. The magnitudes of the gains varied among the populations and environments. The A and F populations gained the most with $96 \%$ and $90 \%$ white seed, respectively, at Dakota Lakes and $88 \%$ and $71 \%$ white seed, respectively, at Brookings. Parents for population A were Alice/CDC Falcon and parents for population F were NuDakota/ Overland.

\section{Selection for red wheat}

Sorting out the white seed from the red population was attempted and was measured as negative gains or reduction in frequency of white seed. The unsorted populations started with low amounts of white seed in their bulk; ranging from $27 \%$ to $14 \%$ to $2 \%$ (Table 1 ). For both Cycle I and II, the reductions in white seeds in the red-sorted populations were negligible in almost all cases. By Cycle III, some reductions of white kernels in the redsorted samples were significant in several populations. Population-A, red-sorted samples started at $27 \%$ white seed and ended at $14 \%$ white seed at $\mathrm{F}_{6}$, but the unsorted reference sample increased its white seed to $51 \%$. Population-F, red-sorted samples started at $2 \%$ in $\mathrm{F}_{3}$ seed and ended at $2 \%$ white seed in $\mathrm{F}_{6}$ seed, but it's unsorted reference sample had increased to $24 \%$ white seed. The sorting helped suppress white seeds in some of the red populations as seen when comparing to the unsorted $\mathrm{F}_{6}$ seed. The red-sorted samples still contained more white seed than desired. Possibly, the genetic variability continued to provide a supply of white seeds. It is difficult to unmask recessive genes while selecting for the dominant gene.

\section{Discussion}

Sorter performance was imperfect: red seed persisted in white-sorted populations and white seed persisted in red-sorted populations. The poor advancement of the white populations during Cycle I was concerning. The sorter was expected to highly purify the samples or at least significantly bias the sub-sample toward white populations. All $\mathrm{F}_{3}$ population samples came from Brookings and weighed $\sim 1250 \mathrm{~g}$ each. These samples were to supply three locations. $\sim 125 \mathrm{~g}$ of white-sorted sample per population was required for this phase of the experiment or $\sim 10 \%$ of the initial $1250 \mathrm{~g}$ sample. Planting $10 \% \mathrm{of}_{3}$ seed 
yielded poor advancement in the white-seed. Regretfully, too many red seeds were included in these sorted samples in order to have enough grain to plant. In Cycle II and III, the populations were harvested at three locations. The amount of white-sorted seed required per harvested population was reduced to $\sim 40 \mathrm{~g}$. Thus, $40 / 1250$ or $\sim 3 \%$ of the $\mathrm{F}_{4}$ and $\mathrm{F}_{5}$ populations were used to advance the white seed. In addition, later populations started with higher concentrations of white seed. The advancement of white-seed was affected by the percentage seed removed and on the initial concentration of the white-seed within that population. In addition, basic variability during plant breeding or genetic interactions may have confounded advancement. Seed breeders often hand select seeds and their sub-samples were probably less than $1 \%$ of the harvested sample. However, in order to test the effectiveness of the sorter and to plant more plots, machine-sorting was tried in an attempt to bias the populations towards the preferred characteristic of white seed color.

Gains from selection for white seed (Fig. 3) were consistently greater at Dakota Lakes than at Brookings in Cycle II and Cycle III. Dakota Lakes and Winner have historically tended to be drier environments than Brookings (Arguez et al. 2010). Kernels harvested from the Dakota Lakes and Winner environment may have had better seed color contrast and produced better sorter calibrations. Several studies have demonstrated that disease, environmental stresses, and weathering, specifically weathering due to moisture, can significantly impact the expression of kernel color and the accurate differentiation of contrasting colors (Wu et al. 1999; Matus-Cadiz et al. 2003; McCaig et al. 2006; Lukow et al. 2013).

Three cycles of sorting for red seed had greater efficacy with A and F populations than other populations. Because red kernel color is dominant (Metzger and Silbaugh 1970), in a population segregating for red alleles at three loci, a high degree of homozygosity would be required before recessive white alleles at all loci are no longer masked by the dominant red alleles. Therefore white alleles cannot be readily eliminated by early-generation selection.

The Cycle I selection on $\mathrm{F}_{3}$ seed had little apparent effect on the frequency of white seed. This study adds consideration to the merit of deferring the optical sorting to bulks until $\mathrm{F}_{4}$ or $\mathrm{F}_{5}$ seed. Deferring color selection one or two generations while applying selection for other key traits, such as disease resistance or winter-hardiness, may achieve comparable improvement in the frequency of white seed while providing greater opportunity to recover desirable genotypes for agronomic traits. Also, as breeders work to develop genotypes tolerant to heat and drought stress, they may consider producing early generations in warmer, drier environments for stress tolerance. These environments appeared to be more favorable for this optical sorting method.

This study looked at multi-year usage of image-based sorting on six hard wheat breeding populations and early generations. The sorter was calibrated with reference parent populations and was used to objectively machine-sort seeds. The sorter was able to sort $1 \mathrm{~kg}$ sized sample in $\sim 30$ minutes. The sorting was able to process samples to supply 108 field plots per year. The sorted purity varied depending on the calibration strength, initial concentration of white seeds, and ejection rate removed from the bulk. Thus, the sorter had certain limits in performance. During this experiment, $\sim 10 \%$ of $\mathrm{F}_{3}$ seed was white- 
sorted and the white population poorly advanced for that season. Later generations used $\sim 3 \%$ of the harvested sample and advancement of white wheat improved significantly. The $\mathrm{F}_{6}$ populations of white-sorted samples from Dakota Lake ranged from $80 \%$ to $92 \%$ white seed. The $\mathrm{F}_{6}$ populations from Brookings ranged from $53 \%$ to $83 \%$ white seed. Four of the unsorted segregating populations (A, D, E, F) increased the percentage of white kernels as genetically expected with 1 or 2 or 3 alleles as seen by the increasing white seed produced in the unsorted samples. Two unsorted populations (B, C) did not increase the percentage of white kernels as genetically expected showing some unintended selection, possibly kernel death or weakening of sprouted white kernels. However, white-sorted portions of the B and C populations from Dakota Lakes reached $80 \%$ white seed by $\mathrm{F}_{6}$. The end result of three successive cycles of optical sorting for early generations were uniformly favorable in selecting white seed.

\section{Acknowledgements}

The authors extend their gratitude to Dr. Bill Berzonsky for his consultation and direction of this project. We are grateful to South Dakota State University Agricultural Experiment Station for the facilities and growing plots. Thanks also are extended to Dr. Kathleen Yeater, USDA-ARS Plains Area Statistician, for review and suggestions with statistical analysis. Mention of trade names or commercial products in this publication is solely for the purpose of providing specific information and does not imply recommendation or endorsement by the U.S. Department of Agriculture. USDA is an equal opportunity provider and employer.

\section{References}

Ambalamaatil, S., Lukow, O.M., Malcolmson, L.J. 2006. Quality attributes of Canadian hard white spring wheat. J. Food Quality 29:151-170.

Arguez, A., Durre, I., Applequist, S., Squires, M., Vose, R., Yin, X., Bilotta, R. 2010. NOAA's U.S. Climate Normals (1981-2010). NOAA National Centers for Environmental Information. DOI:10.7289/V5PN93JP.

Baenziger, P.S., Beecher, B., Graybosch, R.A., Ibrahim, A.M.H., Baltensperger, D.D., Nelson, L., Jin, Y., Wegulo, S., Watkins, J., Hatchett, J.H., Chen, M., Bai, G. 2008. Registration of 'NE01643' Wheat. J. Plant Regist. 2:36-42.

Chang, C.Y., Seitz, L.M., Chambers, E. 1995. Volatile flavor components of breads made from hard red winterwheat and hard white winter-wheat. Cereal Chem. 72:237-242.

Cooper, D.C., Sorrells, M.E. 1984. Selection for white kernel color in the progeny of red white wheat crosses. Euphytica 33:227-232.

Delwiche, S.R. 2008. High-speed bichromatic inspection of wheat kernels for mold and color class using highpower pulsed leds. Sensing and Instrumentation for Food Quality and Safety. 2:103-110.

Dowell, F.E., Maghirang, E.B., Baenziger, P.S. 2009. Automated single-kernel sorting to select for quality traits in wheat breeding lines. Cereal Chem. 86:527-533.

Ibrahim, A.M.H., Haley, S.D., Baenziger, P.S., Jin, Y., Langham, M.A.C., Rickertsen, J., Kalsbeck, S., Little, R., Ingenmansen, J., Chung, O.K., Seabourn, B.W., Bai, G.H., Ming-Shun, C., McVey, D.V. 2008. Registration of 'Alice' wheat. J. Plant Regist. 2:110-114.

Ibrahim, A.M.H., Haley, S.D., Baenziger, P.S., Jin, Y., Langham, M.A.C., Rickertsen, J., Kalsbeck, S., Little, R., Ingenmansen, J., Chung, O.K., Seabourn, B.W., Bai, G.H., Ming-Shun, C., McVey, D.V. 2008. Registration of 'Darrell' wheat. J. Plant Regist. 2:115-119. 
Knott, C.A., Van Sanford, D.A., Souza, E.J. 2008. Comparison of selection methods for the development of white-seeded lines from red $x$ white soft winter wheat crosses. Crop Sci. 48:1807-1816.

Kumar, A., Kumar, J., Singh, R., Garg, T., Chhuneja, P., Balyan, H.S., Gupta, P.K. 2009. QTL analysis for grain colour and pre-harvest sprouting in bread wheat. Plant Sci 177:114-122.

Lukow, O.M., Adams, K., Suchy, J., DePauw, R.M., Humphreys, G. 2013. The effect of the environment on the grain colour and quality of commercially grown Canada hard white spring wheat, Triticum aestivum L. 'Snowbird'. Can. J. Plant Sci. 93:1-11.

Matus-Cadiz, M.A., Hucl, P., Perron, C.E., Tyler, R.T. 2003. Genotype x environment interaction for grain color in hard white spring wheat. Crop Sci. 43:219-226.

McCaig, T.N., Gan, Y.T., Clarke, P., Clarke, J.M., DePauw, R.M. 2006. Kernel colour changes associated with field weathering of spring wheat. Can J. Plant Sci. 86:371-377.

Metzger, R.J., Silbaugh, B.A. 1970. Location of genes for seed coat color in hexaploid wheat, Triticum aestivum L. Crop Sci. 10:495-496.

Paulsen, Q.M., Shroyer, J.P. 2008. The early history of wheat improvement in the Great Plains. Agron. J. 100:S70-S78.

Pearson, T., Brabec, D., Haley, S. 2008. Color image based sorter for separating red and white wheat. Sens. Instr. Food Qual. Safety 2:280-288.

Pearson, T., Maghirang, M., Dowell, F. 2013. A multispectral sorting device for wheat kernels. Am. J. Agric. Sci. and Technol. 2:45-60.

Sherman, J.D., Souza, E., See, D., Talbert, L.E. 2008. Microsatellite markers for kernel color genes in wheat. Crop Sci. 48:1419-1424.

Souza, E.J., Guttieri, M.J., McLean, R. 2004. Registration of 'Gary’ wheat. Crop Sci. 44:1476-1477.

Talbert, L.E., Hofer, P., Nash, D., Martin, J.M., Lanning, S.P., Sherman, J.D., Giroux, M.J. 2013. Hard white versus hard red wheats: Taste tests and milling and baking properties. Cereal Chem. 90:249-255.

Taylor, M.R., Brester, G.W., Boland, M.A. 2005. Hard white wheat and Gold Medal Flour: General Mills' contracting program. Rev. Agr. Econ. 27:117-129.

USDA-FGIS. 2006. Distinguishing between white and red kernels in hard and soft wheat with PotassiumHydroxide Test. Grain Inspection Handbook II, Chpt 13 Wheat. USDA-Federal Grain Inspection Service, Washington, D.C., USA. p. 13-36.

Whan, A.P., Smith, A.B., Cavanagh, C.R., Ral, J.F., Shaw, L.M., Howitt, C.A., Bischof, L. 2014. GrainScan: a low cost, fast method for grain size and colour measurements. Plant Methods 10:23.

Williams, C.L., Felt-Gunderson, P. 2013. Analysis of average daily fiber intake among ready-to-eat cereal consumers: Role of whole-grain cereals in closing the fiber gap. Am. J. of Lifestyle Medicine 7:278-283.

Wu, J.M., Carver, B.F., Goad, C.L. 1999. Kernel color variability of hard white and hard red winter wheat. Crop Sci. 39:634-636.

\section{Electronic Supplementary Material (ESM)}

Electronic Supplementary Material (ESM) associated with this article can be found at the website of CRC at http://www.akademiai.com/content/120427/

Electronic Supplementary Table S1. Analysis of variance of the effect of population and sorting treatment on the frequency of white seed in six $\mathrm{F}_{3}$ populations produced by crossing white and red parents

Electronic Supplementary Table S2. Analysis of variance of fixed effects of location, population, and color selection and their interactions on the proportion of white seed in six segregating populations after each of three cycles of optical selection for seed color

Electronic Supplementary Figure S1. Schematic flow of experiment showing the three cycles of selection for kernel color using of image-sorting in three South Dakota environments 
Electronic Supplementary Figure S2. Frequency of white seeds from trials grown at Winner over sequential cycles of selection

Electronic Supplementary Figure S3. Gains from selection for white seed in six segregating populations after one, two, or three cycles in multiple South Dakota environments

Electronic Supplementary Figure S4. Gain from selection for red seed in six segregating populations after sequential growing cycles in South Dakota environments

Electronic Supplementary Information on agronomic management 